\title{
Study on the Adaptability of Extracting Steam and Heat Return Pipe System of Heating Unit
}

\author{
Liming Zhai ${ }^{1}$, Yaosen Chen ${ }^{2}$, Zhiwei $\mathrm{Li}^{1}$, Xiaochen $\mathrm{Chen}^{2}$, Jiongming Wang ${ }^{1}$, Yinmi Chen ${ }^{2}$, Chanli Yang ${ }^{1}$, \\ Jingming $\mathrm{Liao}^{2}$, Xiaosong $\mathrm{Xia}^{1} \&$ Xiaojia Wang ${ }^{3}$ \\ ${ }^{1}$ Guo Neng (Quan Zhou) Thermal Power Co., Ltd, Quanzhou 362804, China \\ ${ }^{2}$ PowerChina Fujian Electric Power Engineering Co., Ltd, Fuzhou 350003, China \\ ${ }^{3}$ Key Laboratory of Energy Thermal Conversion and Control of Ministry of Education, Southeast University, \\ Nanjing 210096, China \\ Correspondence: Liming Zhai, Guo Neng (Quan Zhou) Thermal Power Co., Ltd, Quanzhou 362804, China.
}

Received: October 15, 2021

Accepted: November 15, 2021

Online Published: November 16, 2021

doi:10.5539/eer.v11n2p71

URL: https://doi.org/10.5539/eer.v11n2p71

\begin{abstract}
In view of the insufficient heating capacity of a supercritical $600 \mathrm{WM}$ unit, it is necessary to determine whether the equipment of the extraction and return heat pipe system can operate normally after the transformation, so as to check the adaptability of the extraction and return heat pipe system equipment of the heating unit. Based on the actual situation and heat balance before and after the transformation of the heating system, this study selects the extracting steam and heat return pipe system of the heating units at all levels, and makes adaptive accounting from the design parameters of the pipeline, and the calculations of steam flow rates or pipe diameters of the pipeline, which provide scientific basis and evaluation for the feasibility of the retrofit scheme.
\end{abstract}

Keywords: combined heat and power generation, heating unit, extracting steam and heat return pipe system, adaptive check

\section{Introduction}

With the development of China's economy and increasing attention to environmental protection, the energy conservation and emission reduction of combined heat and power generation has become a key work of national and local planning (Liu, Zhao \& Pan, 2020; Sun, 2020; Wang \& Liu, 2015). In 2014, the National Development and Reform Commission put forward the requirement of "giving priority to the development of efficient cogeneration units" in the National Climate Change Response Plan (2014-2020). In the same year, the National Development and Reform Commission, the Ministry of Environmental Protection, and the National Energy Administration jointly issued the Action Plan for Upgrading and Transformation of Coal-Fired Power Energy Conservation and Emission Reduction (2014-2020). The document requires the construction of high-efficiency coal-fired thermal power units, and the replacement and phasing out of scattered small coal-fired boilers within the scope of central heating (Sun, 2020; Guo, Hu, Wan, Xie, Yang \& Shen, 2015; Liao, 2014; Yang, Huang \& Ma, 2017; Wan, Sun, Ge \& He, 2016; Zhang, 2014).

A power plant company installed two units of $300 \mathrm{MW}$ for the first phase, and two more units of $670 \mathrm{MW}$ for the second phase, all of which have undergone heating transformation. In Phase I, the heat is supplied after temperature and pressure reduction of the main steam, resulting in great exergy loss and low overall thermal economy of the units. Besides, the regulation mode of medium-pressure regulating valve throttling is adopted in phase II, which shows poor economic benefits and potential safety hazards. Although the cogeneration units of this company have large heating capacity, the energy-saving effect of these units is little. For example, the coal consumption of Phase I units is still more than $310 \mathrm{~g} / \mathrm{kWh}$ under cogeneration conditions. On the other hand, after experiencing rapid growth, China's power industry is facing problems of continuous deterioration of the operating environment, such as the high fuel cost and the reduction of unit utilization hours. Although the growth of investment in the coal industry is gradually alleviating the imbalance between coal supply and demand markets, the power industry still needs to face the operation pressure caused by the reduction of unit utilization hours in the future. Under such a severe market environment and cruel competition situation, the high energy consumption operation of units will greatly affect the development of the enterprise itself. Therefore, it is necessary to adopt advanced and mature 
technologies to transform the primary unit for energy conservation and efficiency enhancement, so as to improve the heating performance of the unit and reduce the coal consumption of power generation and supply (Wan, Sun, Ge \& He, 2016; Xu, Zhou \& Wang, 2014; Ge, Sun, Wan, Zhao \& He, 2017).

The transformation design of the company is the system design from the main engine to the first heating station of Phase I. The first heating station is the terminal of this optimized design. Through flow transformation, the flow efficiency of the unit will be improved, and the heating capacity of the first extraction will be expanded considering the heating demand. In order to ensure the operation of the steam extraction and regenerative system pipeline after transformation, the adaptability of each steam extraction pipeline needs to be checked (Wang, 2017; Huang, 2018; Zhai, 2012). Based on the actual situation and heat balance diagram of the company before and after the transformation of the heating system, this study makes adaptability accounting for the extraction and heat regenerative pipeline system of heating units at all levels, judges its adaptability after the transformation, and provides a scientific basis for the feasibility of the scheme, so as to make an accurate judgment.

\section{General Idea for Verification of Regenerative Pipeline System}

The overall verification idea of the regenerative pipeline system after the heating supply transformation of the company's power plant is shown in Figure 1. According to the actual situation and heat balance before and after the transformation, firstly, we calculate the pipeline design parameters of Section I to Section VI steam extraction pipelines and steam source extraction pipelines of feed pump steam turbine, and compare the extraction pressures and extraction temperatures of VWO before transformation, TMCR after transformation, VWO after transformation and existing pipeline design, to check whether the parameters of the pipelines can match the parameters of working fluid in the pipelines after transformation. Secondly, the flow rate of working fluid in the pipe changes greatly after the transformation, while the recommended flow rate of steam in the extraction and regenerative pipeline system for heating supply units after the transformation is $35 \sim 60 \mathrm{~m} / \mathrm{s}$. Therefore, this work takes the steam flow rates under the TMCR working condition, average heating working condition, rated heating working condition and maximum heating working condition, and compares them with the recommended steam flow rate of steam extraction and regenerative pipeline system for heating supply units, so as to adjust the pipeline steam flow rate/pipe diameter, and put forward the corresponding solutions for the overspeed flow sections.

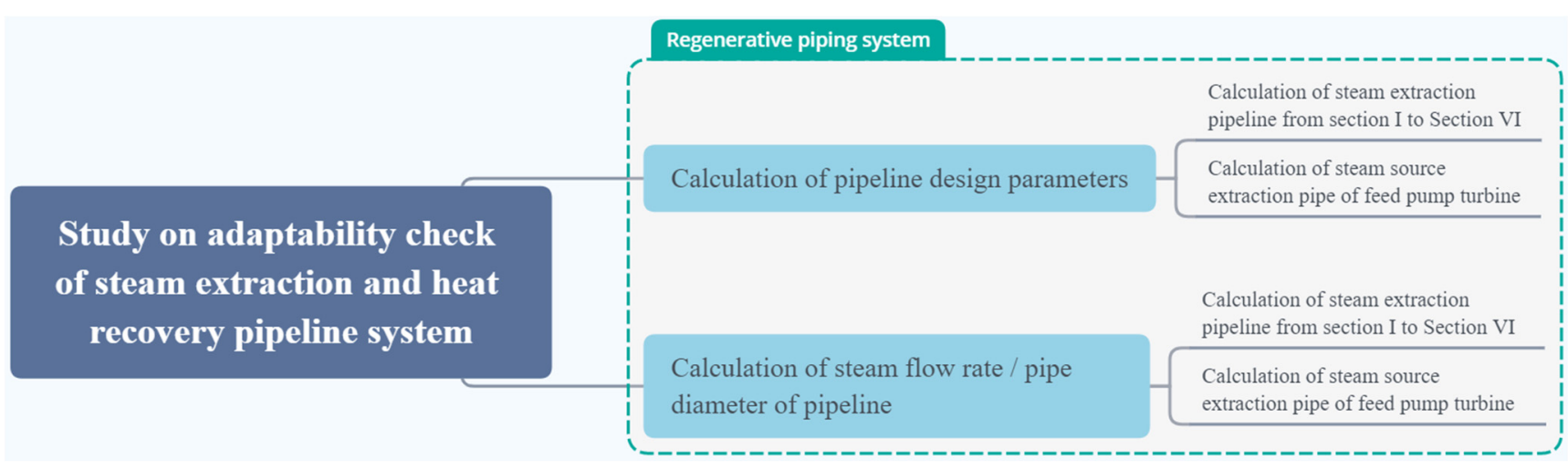

Figure 1. The accounting logic of the regenerative pipeline system after the heating supply transformation

\section{Accounting of Pipeline Design Parameters}

The two $300 \mathrm{MW}$ steam turbines after transformation have been operated under the TMCR condition, and the inlet and outlet pressures and temperatures of reheat steam do not exceed the design values of boiler BMCR condition (i.e. steam turbine VWO condition) before transformation. 

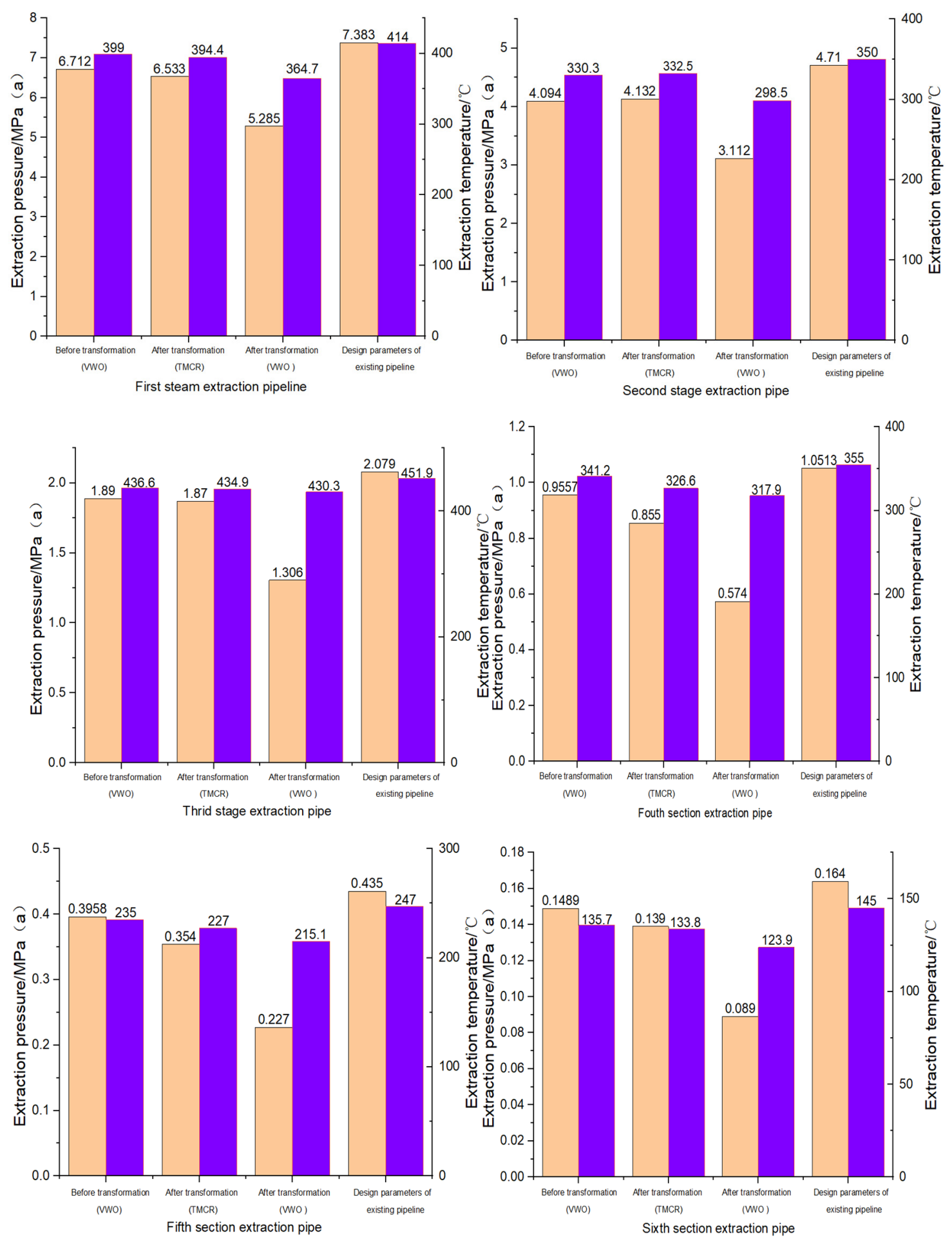

Figure 2. Comparison of working condition parameters of each extraction pipeline

Figure 2 shows the comparison of extraction pressures and temperatures among VWO condition before transformation, TMCR condition after transformation, VWO condition after transformation, and existing pipeline design parameters for Section I to Section VI extraction pipelines. It can be seen from the figure that the extraction temperatures and pressures under VWO and TMCR conditions after transformation do not exceed the design value of the existing pipeline. In detail, the TMCR parameters of steam extraction pipelines of section I, Section III, Section IV, Section V and section VI after transformation are all lower than the VWO working conditions before transformation. Only those of Section II are slightly higher than the VWO working conditions before the transformation (the pressure increases from 4.094 MPa to 4.132 MPa and the temperature changes from $330.3{ }^{\circ} \mathrm{C}$ 
to $332.5^{\circ} \mathrm{C}$ ). The design parameters of the existing pipeline are selected according to the VWO conditions before the transformation, and the corresponding requirements of Design Code of Steam and Water Pipelines in Thermal Power Plants (DLT 5054-2016). Therefore, considering the actual operating conditions, the design parameters of the existing steam extraction pipelines of Section I, Section II, Section III, Section IV, Section V and Section VI can meet the needs of TMCR operating requirements after the transformation.

The steam source extraction pipeline of feed pump turbine is a new pipeline, and its steam source is from Section IV extraction pipeline. The comparison of working conditions of steam source extraction pipeline of feed pump turbine is shown in Figure 3. The design parameters of the pipeline were reselected according to the design code of steam water pipeline of thermal power plant (DLT 5054), and the design parameters were all improved, especially the design temperature, increasing from $355^{\circ} \mathrm{C}$ to $406.39{ }^{\circ} \mathrm{C}$. Through calculation, the low-pressure steam inlet pipe diameters of raw feed pump turbine $(\varphi 325 \times 8$ and $\varphi 273 \times 7)$, and pipe fittings can meet the new design parameters. The pressure grade of the valves (electric gate valve, swing check valve, first drain shut-off valve, etc.) on the steam inlet pipe of the original small turbine is PN25, which are connected with flanges. According to the regulations on valve pressure-temperature rating in the guidelines for ordering and acceptance of steel general valves for thermal power generation (DLT 922-2016), the existing valves with flange connection (electric gate valve, swing check valve, etc.) cannot meet the corresponding pressure-temperature grade reduction in the specification due to the improvement of pipeline design parameters, so they need to be upgraded.

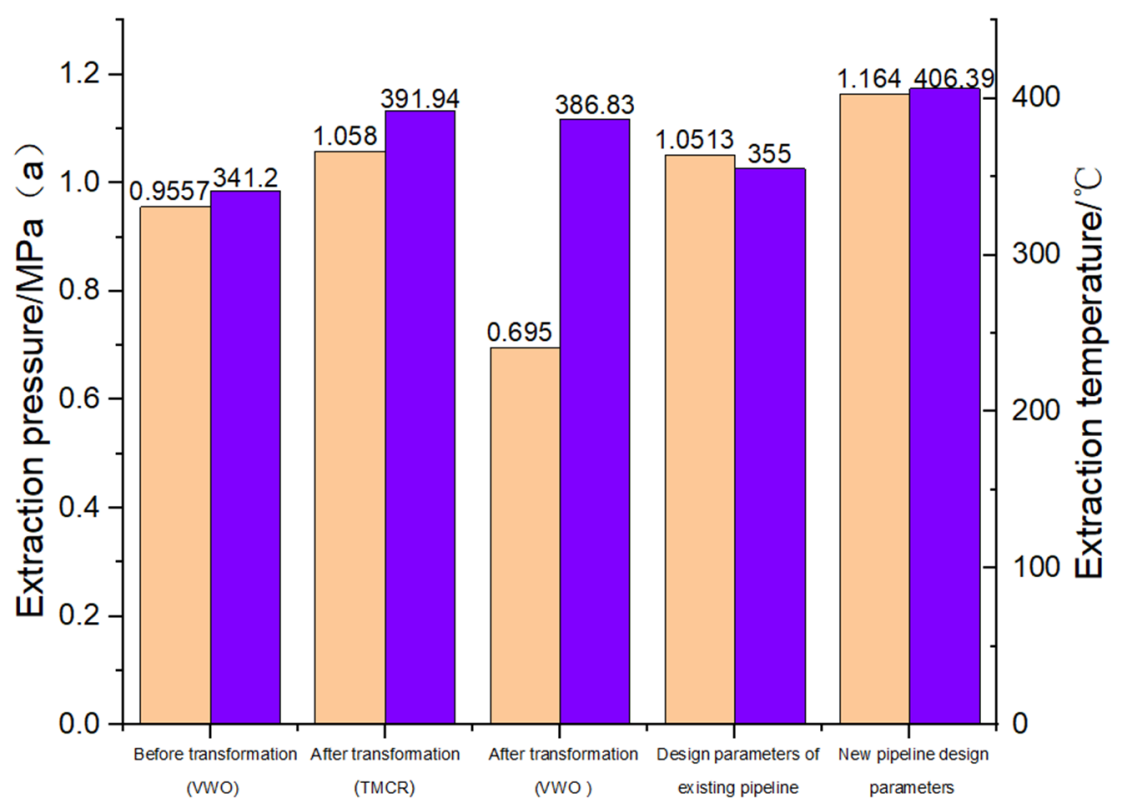

Figure 3. Comparison of working conditions of steam source extraction pipeline of feed pump turbine

\section{Accounting of Steam Flow Rate / Pipe Diameter of Pipeline}

According to Design Code of Steam and Water Pipelines in Thermal Power Plants (DLT 5054-2016), the recommended steam velocity of extraction and regenerative pipeline system of a heating supply unit after transformation is between 35 and $60 \mathrm{~m} / \mathrm{s}$. Therefore, the pipeline velocity is the basis for selecting pipe diameter. Through calculation and analysis, the working condition with the maximum steam flow rate is the maximum heating working condition or rated heating working condition. 

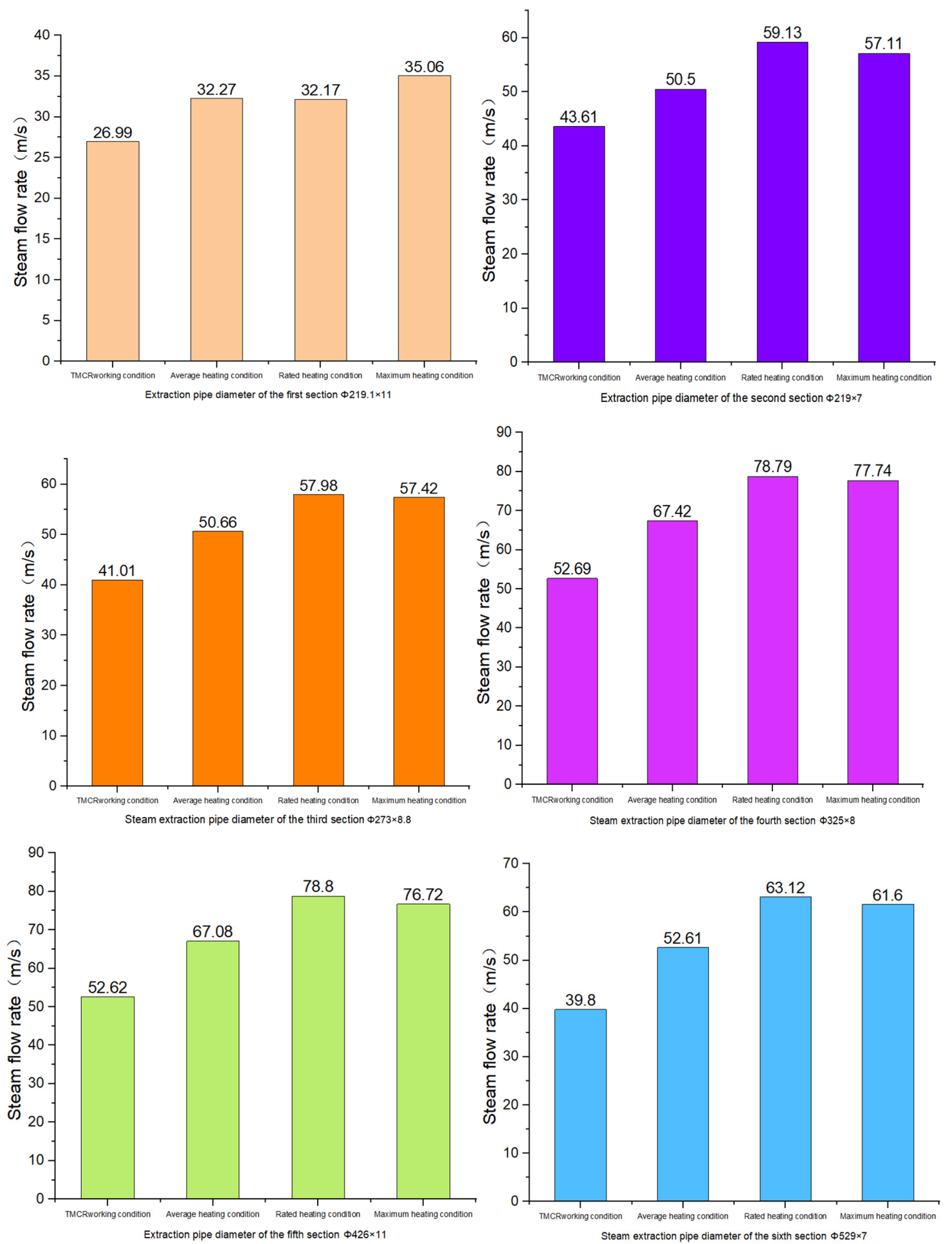

Figure 4. Comparison of steam flow rate of each extraction pipeline under different working conditions

Figure 4 shows the steam flow rates in the steam extraction pipeline from Section I to Section VI under TMCR condition, average heating condition, rated heating condition and maximum heating condition after transformation. It can be seen that the steam flow rates from Section I, Section II and Section III of steam turbine can meet the above recommended flow rate range, and the pipeline can adapt to the operating conditions after transformation. Section VI of steam turbine slightly exceeds $60 \mathrm{~m} / \mathrm{s}$ under rated heating condition or maximum heating condition, while its flow rate is $52.61 \mathrm{~m} / \mathrm{s}$ under average heating condition, so expansion replacement is not considered. Besides, under the rated heating condition, the steam flow rate from part of the steam extraction pipe of Section IV to the steam pipe of the deaerator reaches $78.79 \mathrm{~m} / \mathrm{s}$, which needs to be expanded and replaced in general. 
Under the rated heating condition, the steam flow rate of Section $\mathrm{V}$ reaches $78.80 \mathrm{~m} / \mathrm{s}$. Hence, this section also needs to be expanded and replaced. Therefore, it is considered to increase the pipe diameter of Section IV from $\varphi$ $325 \times 8$ to $\varphi 377 \times 10$ while the diameter of Section $V$ increasing from $\varphi 426 \times 11$ to $\varphi 508 \times 9$.

Before and after expansion, the comparison of steam flow rates in Section IV and V pipelines under TMCR condition, average heating condition, rated heating condition and maximum heating condition is shown in Figure 5. It can be found that the steam flow rates in Section IV and V pipelines after transformation have decreased to the recommended values. In detail, the steam flow rate in Section IV under rated heating working condition is $59.03 \mathrm{~m} / \mathrm{s}$ while that in Section V is $56 \mathrm{~m} / \mathrm{s}$. After the expansion of the two sections, the pipeline layout follows the principle of existing pipeline path to reduce the impact on the surrounding pipelines and avoid adjusting and dismantling other pipelines. Since the valves on the steam extraction pipeline from Section IV to deaerator and Section V can meet the requirements of temperature-pressure level after transformation, they will not be replaced. When the straight pipe section between valves is too short, there are no enough space for placing two reducers, or the original support and hanger position cannot be maintained. In this case, the straight pipe section will not be considered for diameter expansion. Other local positions are combined with the existing pipeline layout. For other special features, such as the direct connection between the reducer and the elbow, the diameter expansion will not be considered, either. These positions are not at the corresponding low-pressure heater inlet, and hence will not lead to the steam overspeed at the low-pressure heater inlet.
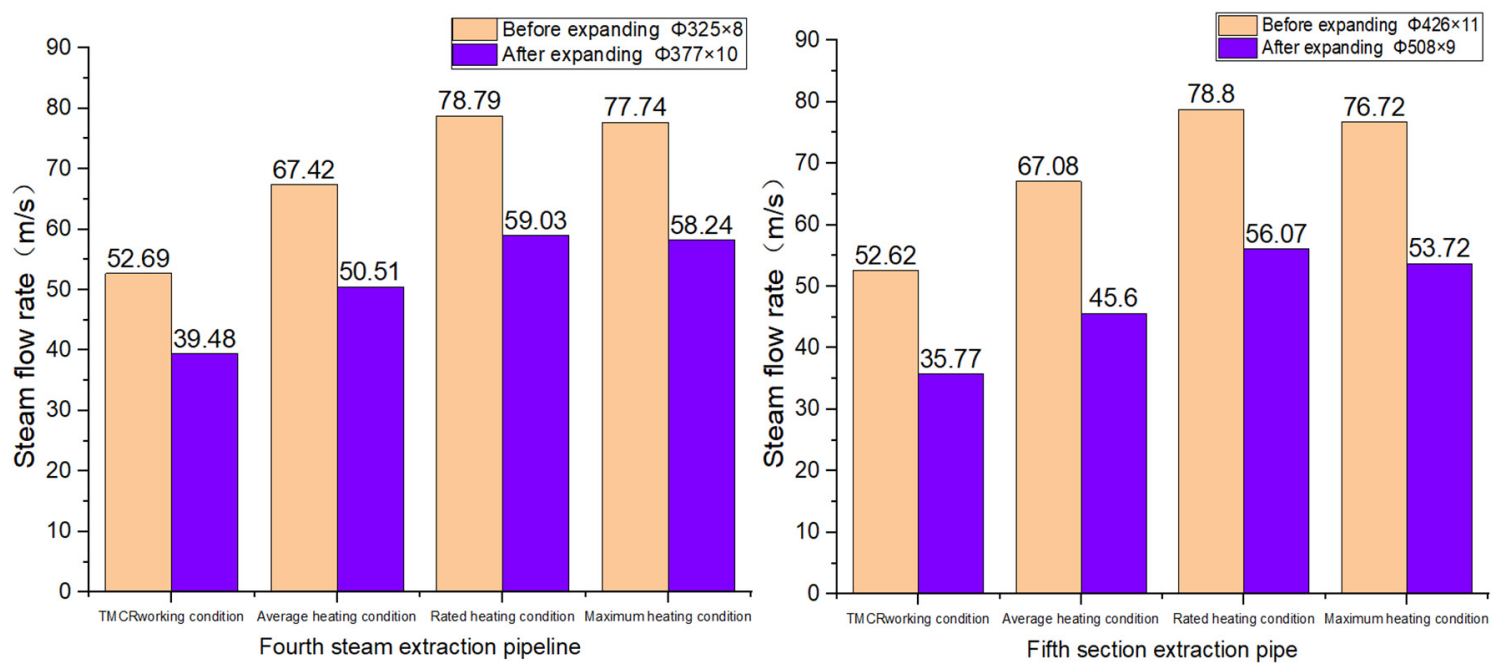

Figure 5. Comparison of Section IV and Section V steam extraction pipelines before and after transformation

Figure 6 shows the steam flow rates in the two steam inlet pipes of feed pump turbine under TMCR working condition, average heating working condition, rated heating working condition and maximum heating working condition after transformation. It can be found that the flow rates in the pipe under different working conditions after transformation meet the recommended value range. Specifically, the steam flow rate in inlet pipe 1 of the feed pump turbine under rated heating working condition is $53.74 \mathrm{~m} / \mathrm{s}$. while that in the feed pump turbine pipe 2 is $38.25 \mathrm{~m} / \mathrm{s}$. Therefore, the expansion replacement is not considered. 

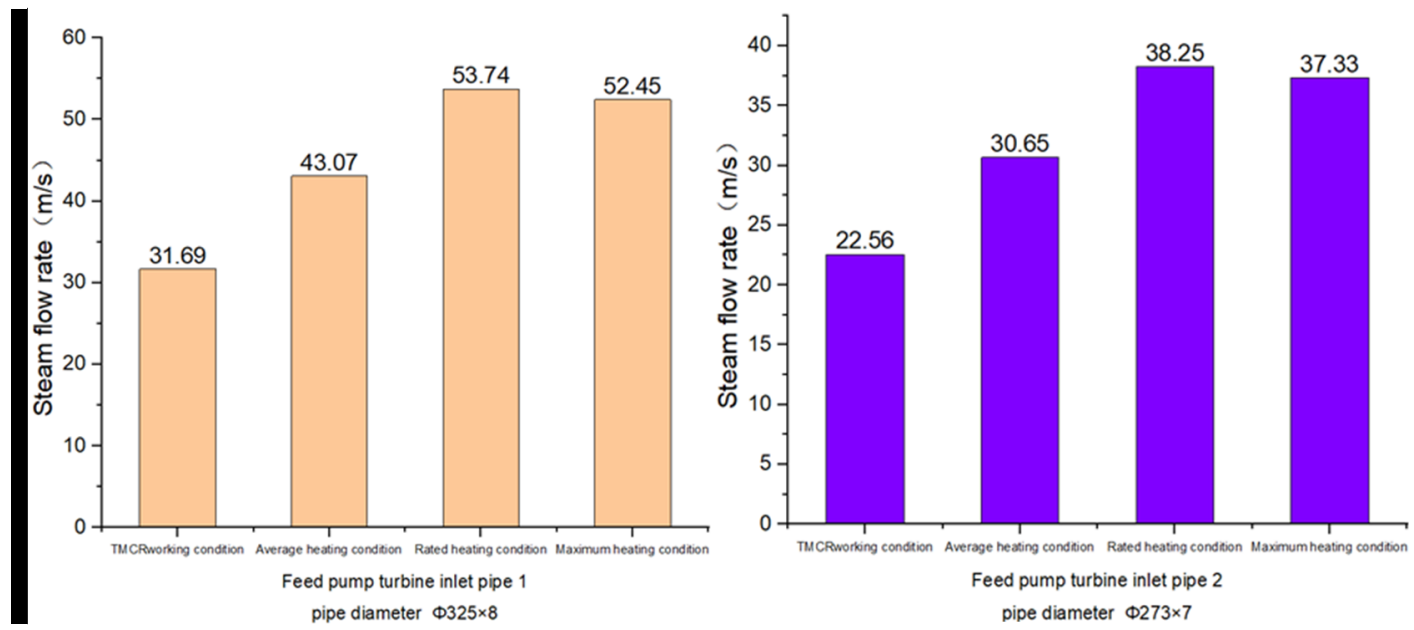

Figure. 6 Comparison of steam flow rate in the feed pump turbine pipes under different working conditions

\section{Conclusion}

In order to improve energy utilization efficiency, unit reliability and flexibility, and meet the needs of new heat users in the future, the heating system of a power plant is transformed again on the basis of the transformation of phase I and phase II project. In order to ensure the operation of the extraction and regenerative system pipelines after the transformation, the adaptability of each extraction pipe needs to be checked. According to the actual situation and heat balance diagram of the heating system before and after the transformation, this study carries out the adaptability accounting of steam extraction and heat recovery pipeline system of heating units at all levels. The main conclusions can be drawn as follows:

(1) Considering the TMCR parameters of the steam extraction pipelines of Section I, Section III, Section IV, Section V and Section VI of the steam turbine after the transformation are all lower than the VWO conditions before the transformation, and the corresponding parameters of Section II are slightly higher, the design parameters of the steam extraction pipelines of Section I to Section VI can meet the needs of the TMCR operating parameters after the transformation.

(2) According to the provisions on the pressure-temperature rating values of valves, the steam source extraction pipeline of feed pump turbine cannot meet the corresponding pressure-temperature grade reduction in the specification due to the improvement of pipeline design parameters. Hence, it needs to be upgraded and changed.

(3) The steam flow rates of Section I, Section II and Section III of steam turbine and steam inlet pipeline of small turbine can meet the recommended steam flow rate of steam extraction pipeline, so it does not need to be modified. The maximum steam flow rate of Section VI slightly exceeds the recommended value. Hence no modification is required, but the working conditions need to be limited. Besides, the steam flow rates of Section IV and Section V under the rated working conditions has exceeded the recommended values. Hence, it is necessary to expand the diameter.

\section{References}

Ge, Z. H., Sun, S. M., Wan, Y., Zhao, S. F., \& He, J. R. (2017). Applicability analysis of high back pressure heating transformation of large steam turbine unit. Chinese Journal of electrical engineering, 37(11), 3216-3222 + 3377.

Guo, Y. H., Hu, B., Wan, L. Y., Xie, K. G., Yang, H. J., \& Shen, Y. M. (2015). Short term optimal economic operation of cogeneration microgrid with heat pump. Power system automation, 39(14), 16-22.

Huang, T. (2018). Analysis on design points of steam turbine regenerative extraction system. Southern energy construction, 5(01), 68-72.

Liao, C. H. (2014). Research on optimal allocation of heat sources in coal-fired cogeneration district heating system. Harbin University of technology, 2014

Liu, Z. Q., Zhao, Y., \& Pan, L. (2020). Analysis and comparison of energy conservation and emission reduction efficiency of thermal power at home and abroad. Thermal power generation, 1-10.

Sun, T. H. (2020). Evaluation of energy efficiency index of back pressure cogeneration unit. Energy saving, 39(09), 
49-53.

Wan, Y., Sun, S. M., Ge, Z. H., \& He, J. R. (2016). Thermal economic analysis of high back pressure heating transformation of large cogeneration units. Power construction, 37(04), 131-137.

Wang, B., \& Liu, G. T. (2015). Energy conservation and emission reduction and China's green economic growth - from the perspective of total factor productivity. China industrial economy, 2015(05), 57-69.

Wang, P. (2017). Research on energy efficiency evaluation and diagnosis of steam extraction and heat recovery system of million ultra supercritical units. North China Electric Power University (Beijing), Doctoral Dissertation.

Xu, T., Zhou, Y., \& Wang, X. L. (2014). Research on peak shaving capacity of 300MW cogeneration unit. China power, 47(09), 35-41.

Yang, C., Huang, Z. F., \& Ma, X. X. (2017). Off design performance analysis of combined cycle cogeneration units. Proceedings of the CSEE, 37(12), 3514-3524 + 3680.

Zhai, L. Q. (2012). Reasonable optimization of regenerative steam extraction system. Silicon Valley, 06, 192.

Zhang, Y. L. (2014). Application Research of cogeneration central heating based on absorption heat exchange. Jilin Architecture University. Doctoral Dissertation.

\section{Copyrights}

Copyright for this article is retained by the author(s), with first publication rights granted to the journal.

This is an open-access article distributed under the terms and conditions of the Creative Commons Attribution license (http://creativecommons.org/licenses/by/3.0/). 